This site uses cookies. More info $\boldsymbol{\otimes}$ Close By continuing to browse the site you are agreeing to our use of cookies. Find out more here Close

thebmi

\title{
Editorials
}

\section{Antimicrobials in children admitted to hospital in malaria endemic areas}

BMJ 2010; 340 doi: http://dx.doi.org/10.1136/bmj.c1818 (Published 08 April 2010) Cite this as: BMJ 2010;340:c1818

\author{
Kathryn Maitland, professor in tropical paediatric infectious diseases \\ ${ }^{1}$ Department of Paediatrics, Division of Medicine, Imperial College, London W2 1PG
}

kathryn.maitland@gmail.com

Identifying children with sepsis is the first major challenge

The cornerstones of the Surviving Sepsis Campaign are the prompt identification of sepsis and the subsequent implementation of evidence based treatments.1 A key component of this strategy is the timely use of antibiotics. Even in countries embracing these guidelines, "sepsis" is largely diagnosed clinically, so prompt recognition and treatment should be possible even for hospitals with basic clinical and diagnostic capabilities. What are the barriers to the implementation of this goal and, more specifically, to the targeted antimicrobial treatment of children admitted to hospital in malaria endemic Africa? In the linked prospective study (doi:10.1136/bmj.c1350), Nadjm and colleagues assess the performance of the World Health Organization's referral care manual (which guides the use of antibiotics in children admitted to hospital in Africa) in identifying children with invasive bacterial disease in an area of intense malaria transmission.2

Four major challenges exist. Firstly, presentation to hospital with febrile disease is extremely common, so making informed choices about who to treat with parenteral antibiotics needs to be balanced against overtreatment. Secondly, in malaria endemic areas, children often carry falciparum malaria asymptomatically, so malaria is overdiagnosed at the expense of other infectious conditions. Evidence also suggests that accurate microscopy has limited influence on prescribing practice. 3 Thirdly, complex, patient specific prescribing is not encouraged. The limited pharmacopoeia, driven largely by cost, is poorly informed by clinical audit. Good epidemiological evidence is hard to find because routine microbiological investigation is scarce and reports are limited to a few research centres.4 Finally, the term sepsis, which broadly implies a sepsis-like syndrome, $\mathbf{5}$ is not even mentioned in referral care practice guidelines. 6 Instead, probably for historical programmatic reasons, treatment strategies are largely limited to one syndrome, so treatment of suspected bacterial infection is covered separately in other management guidelines. Practically, this presents 
challenges for bedside management because many children present with clinical features of multiple syndromes. 7

Nadjm and colleagues describe a prospective microbiological study of 3639 febrile children, median age 1.6 years, presenting to a rural hospital in a highly malarious area of Tanzania, where immunisation for Haemophilus influenzae or Streptococcus pneumoniae is not routine.2 Children were systematically screened for malaria and invasive bacterial disease by culture of blood and cerebrospinal fluid (where indicated). The unique component of this study was assessment of the performance of the WHO first level care guidelines to identify children with invasive bacterial disease by applying the case definitions retrospectively and with respect to malaria status. Overall, 341 (9\%) cases had invasive bacterial disease, of which $58(17 \%)$ episodes were fatal. One hundred and forty two children had HIV infection. Current or recent falciparum infection occurred in 2195 (60\%) admissions; 100 (4.5\%) of these children had invasive bacterial disease. Mortality was higher in children with invasive bacterial disease $(17 \%$ v $4 \%)$, irrespective of malaria status. Importantly, clinical diagnosis alone, using WHO classification, failed to identify $30 \%$ of all invasive bacterial disease and $17 \%$ of fatal invasive bacterial disease cases. The sensitivity of the guidelines to detect invasive bacterial disease were $60 \%$ and $70 \%$ in malaria and non-malaria cases, respectively. Improvements in the specificity to $86 \%$ could be gained by addition of HIV status (now routine in paediatric admissions), severe anaemia (haemoglobin $<50 \mathrm{~g} / \mathrm{l}$, prostration (decreased consciousness), and high fever, but at the expense of poor specificity (22-29\%). Only $47 \%$ of organisms were susceptible to the antibiotics recommended for the clinical diagnosis. The guideline was best at detecting meningo-encephalopathy when the organisms were predominantly Gram positive (96\% were sensitive to the ampicillin-gentamicin combination). The guideline performance was poorest in children with malaria, where $75 \%$ of invasive bacterial disease was with Gram negative bacteria; both non-typhoidal salmonellae and other Gram negative bacteria were common. Non-typhi salmonella more commonly complicated cases of recent malaria or those with densities of less than 5000 parasites/ $\mu$ l, whereas other Gram negative bacteria were the predominant organisms in cases with higher densities.

This study adds to the growing literature on the epidemiology of invasive bacterial disease in malaria endemic areas, and it shows that non-typhoidal salmonellae contribute substantially to the spectrum of infection.8 910 Even for those presenting with one of the three hierarchical definitions of "pneumonia" severity, non-typhoidal salmonella was still the predominant pathogen, and treatment would have been either with oral antibiotics or parenteral penicillin. Another limitation of "syndromic" management is seen in children with a respiratory-type presentation, who are routinely classified as having pneumonia and managed as such. Although the case definition for severe malaria incorporates respiratory distress (a manifestation of metabolic acidosis), which is a common complication and the best independent predictor of fatal outcome,11 the disease may be misclassified as pneumonia.12 For severe malaria no specific recommendations for antibiotics are made in the hospital management guideline.

This study highlights the inadequacy of the time honoured antibiotics that are in routine use across Africa, and that are likely to remain unchanged even after immunisation for $H$ influenzae and $S$ pneumoniae is introduced into malaria endemic Africa. Notwithstanding arguments for rational antibiotic prescribing practices, Nadjm and colleagues' study highlights the need to consider third 
generation cephalosporins or quinolones for future trials and treatment guidelines. Nevertheless, correct identification of children with sepsis in resource poor settings continues to be a major practical, clinical, and therapeutic challenge.

\section{Notes}

Cite this as: $B M J$ 2010;340:c1818

\section{Footnotes}

- Research, doi:10.1136/bmj.c1350

- Competing interests: The author has completed the Unified Competing Interest form at www.icmje.org/coi disclosure.pdf (available on request from the corresponding author) and declares: (1) No financial support for the submitted work from anyone other than her employer; (2) No financial relationships with commercial entities that might have an interest in the submitted work; (3) No spouse, partner, or children with relationships with commercial entities that might have an interest in the submitted work; (4) No non-financial interests that may be relevant to the submitted work.

- Provenance and peer review: Commissioned; not externally peer reviewed.

\section{References}

1. Dellinger RP, Carlet JM, Masur H, Gerlach H, Calandra T, Cohen J, et al. Surviving Sepsis Campaign guidelines for management of severe sepsis and septic shock. Crit Care Med2004;32:858-73.

2. Nadjm B, Amos B, Mtove G, Ostermann J, Chonya S, Wangai H, et al. WHO guidelines for antimicrobial treatment in children admitted to hospital in an area of intense Plasmodium falciparum transmission: prospective study. BMJ2010;340:c1350.

3. Reyburn H, Mbatia R, Drakeley C, Carneiro I, Mwakasungula E, Mwerinde O, et al. Overdiagnosis of malaria in patients with severe febrile illness in Tanzania: a prospective study. BMJ2004;329:1212.

4. Berkley JA, Maitland K, Mwangi I, Ngetsa C, Mwarumba S, Lowe BS, et al. Use of clinical syndromes to target antibiotic prescribing in seriously ill children in malaria endemic area: observational study. BMJ 2005;330:995.

5. Goldstein B, Giroir B, Randolph A. International pediatric sepsis consensus conference: definitions for sepsis and organ dysfunction in pediatrics. Pediatr Crit Care Med 2005;6:2-8.

6. WHO. Hospital care for children: guidelines for the management of common illnesses with limited resources. 2005. www.who.int/child-adolescent-health/publications/CHILD_HEALTH/PB.htm.

7. Berkley JA, Bejon P, Mwangi T, Gwer S, Maitland K, Williams TN, et al. HIV infection, malnutrition, and invasive bacterial infection among children with severe malaria. Clin Infect Dis 2009;49:336-43.

8. Walsh AL, Phiri AJ, Graham SM, Molyneux EM, Molyneux ME. Bacteremia in febrile Malawian children: clinical and microbiologic features. Pediatr Infect Dis J2000;19:312-8.

9. Bahwere P, Levy J, Hennart P, Donnen P, Lomoyo W, Dramaix-Wilmet M, et al. Community-acquired bacteremia among hospitalized children in rural central Africa. Int $J$ Infect Dis 2001;5:180-8. 
10. Berkley JA, Lowe BS, Mwangi I, Williams TN, Bauni E, Mwarumba S, et al. Bacteremia amongst children admitted to a rural hospital in Kenya. N Engl J Med2005;352:39-47.

11. Marsh K, Forster D, Waruiru C, Mwangi I, Winstanley M, Marsh V, et al. Indicators of life-threatening malaria in African children. N Engl J Med1995;332:1399-404.

12. English M, Punt J, Mwangi I, McHugh K, Marsh K. Clinical overlap between malaria and severe pneumonia in Africa children in hospital. Trans R Soc Trop Med Hyg 1996;90:658-62. 